\section{Loophole in forest plan for Indonesia}

Last year, Indonesia and Norway signed the Oslo Pact, which will pay Indonesia up to US\$1 billion to reduce carbon emissions by advancing forest-conservation initiatives. As part of the deal, Indonesia must halt the licensing of new agricultural plantations and logging concessions on peatlands and natural forest for two years. Clearing and logging must instead be directed to nonforest 'degraded' lands and to existing concessions. But the pact has a big loophole.

Indonesia is the world's thirdlargest emitter of greenhouse gases, caused mostly by rampant felling or burning of its rainforests and carbon-rich peatswamp forests. The loss of these ecosystems also threatens major hot spots of global biodiversity. The hope is that the Oslo Pact and follow-on carbon payments can stem this tide.

However, President Susilo Bambang Yudhoyono of Indonesia has issued a two-year moratorium on new concessions for clearing or logging of peatlands and natural primary (old-growth) forest. Contrary to the Oslo Pact, vast expanses of selectively logged forests - which sustain substantial carbon stores and much biodiversity - are classed as 'degraded' and left out of the moratorium altogether. The net effect is that these natural forests could be re-logged or cleared for oil palm and pulpwood plantations. According to its Ministry of Forestry, Indonesia has 35.4 million hectares of logged forest that can be cleared, considerably more than the upper estimate of 20 million hectares of primary forest protected under the moratorium.

Many protected forests are in steep, mountainous areas that face little threat. The most imperilled forests, in the lowlands, are largely excluded from the deal because they have been logged previously. On top of this, the moratorium fails to protect shallow peatlands from conversion, or halt primary forests and deep peatlands from being cleared for sugar cane one of the most rapidly expanding biofuel crops.

We urge Norway to insist that logged forests and clearance for sugar cane be included under the moratorium. Without doing so, this is little more than business as usual in Indonesia.

David P. Edwards, William F. Laurance James Cook University, Cairns, Queensland, Australia. dave.edwards@jcu.edu.au

\section{Call to save science institute in Turkey}

On 15 July, the Turkish Scientific and Technological Research Council (TÜBİTAK) effectively closed down the Feza Gürsey Institute for Basic Sciences in Istanbul by relocating it to a TÜBİTAK cryptology institute in Gebze. More than 1,500 signatures were collected by mid-August to ask the science minister, Nihat Ergün, to reconsider this decision.

The Feza Gürsey Institute, named after an eminent Turkish physicist, has been crucial in the training of Turkish researchers. In the words of Marta Sanz-Solé, president of the European Mathematical Society, it is central to the "consolidation of scientific international collaborations".

The institute has a remarkable research record in theoretical physics and mathematics that spans 14 years, with 350 articles published in high-profile journals and more than 2,000 citations. It has hosted international meetings and free summer schools for thousands of Turkish participants.

The move seems to be an example of TÜBİTAK's apparently low rating of basic research and its relation to applied research and technology.

Signatories in the campaign to save the institute include more than 100 prominent physicists and mathematicians, as well as the presidents of the US, European and French mathematical societies, and of Turkey's Mathematical Society, Physical Society and Astronomical Society (http:// savefezagursey.wordpress.com). Ayşe Erzan Istanbul Technical University, Turkey. erzan@itu.edu.tr

Cihan Saçlığlu Sabancı

University, Turkey.

\section{Drug firm monitors waste water}

At AstraZeneca we are proactively addressing the problem of pharmaceuticals entering the environment as a result of our manufacturing discharges

(Nature 476, 265; 2011).

Using ecotoxicity data and our knowledge of environmental fate and the local environment, we have identified long- and short-term concentrations of active pharmaceutical ingredients that we refer to as Environmental Reference Concentrations (ERCs) and Maximum Tolerable Concentrations (MTCs), respectively. These should not be exceeded in the aquatic environments that receive effluent from our manufacturing sites.

This approach is based on established environmental quality standards used in national and international legislation. Under this voluntary initiative, we have so far established ERCs and MTCs for 30 of our active pharmaceutical ingredients to protect the freshwater environment (algae, invertebrates and fish), top predators (fisheating mammals such as otters), the marine environment (for coastal discharges) and humans. Other research-based pharmaceutical industries also have voluntary initiatives to control their discharges.

We have 'ecopharmacovigilance' procedures in place to ensure that our ERCs continue to take into account all relevant data and current scientific understanding of the fate and effects of pharmaceuticals in the environment. For example, if a new, lower, no-effect concentration is reported in the peer-reviewed literature and is scientifically robust, we revise our ERCs and environmental risk assessments accordingly.

Last year, we started a programme to monitor our own emissions against ERC and MTC values for our worldwide sites that could discharge waste water containing active pharmaceutical ingredients during peak production. We are now starting to share the ERC approach with our third-party manufacturers, with a view to including them in the programme.

Jason Snape, Chris Lewis, Richard Murray-Smith AstraZeneca, Brixham Environmental Laboratory, UK. richard.murray-smith@

astrazeneca.com

Competing financial interests declared. See go.nature.com/e6tkkb.

\section{Diploma database to encourage mobility}

Researchers moving abroad often need to have their qualifications recognized by a local university or other national institution. This costly process can take months, and may include thesis re-evaluation by a panel of professors or researchers. Add to this the extensive paperwork already required for applications for jobs, research grants or scholarships, and the need to cut red tape to encourage mobility within the scientific community becomes more pressing.

Governments and universities should create an international online database that details the qualifications of applicants from foreign universities, together with a summary of the work entailed and the standard expected.

Decisions by institutions responsible for recognizing diplomas awarded abroad would then be just a few clicks away. Ana M. C. Santos Federal University of Goiás, Goiânia, Brazil.ana.margarida.c.santos@ googlemail.com 